Title: Effect of continuous water steam explosion on crystalline structure of microcrystalline cellulose

Authors: Zhengwen $\mathrm{Li}^{1}$, Jian Xiong ${ }^{1}$, Jun $\mathrm{Ye}^{2}$

(1. School of Food Science and Engineering, South China University of Technology, Guangzhou 510640, China; 2. South China University of Technology, Guangzhou 510640, China)

\title{
Original abstract:
}

Continuous steam explosion was applied to preprocess microcrystalline cellulose(MCC), and the changes in crystalline structure of MCC were studied. All samples preprocessed showed a typical cellulose I crystal structure by XRD (Figure). However, the degrees of crystalline (Xc) of all samples preprocessed decreased, compared with raw MCC. The band of all samples preprocessed around at $3414 \mathrm{~cm}^{-1}$, assigned to-OH stretching vibrations, was sharper and narrower than the band of raw MCC. Moreover, the bands were resolved into three peaks by Gaussian function[1], these were at $3551 \mathrm{~cm}^{-1}, 3350 \mathrm{~cm}^{-1}$ and $3164 \mathrm{~cm}^{-1}$, assigned to the intramolecular hydrogen bond of 2-OH...O-6, intramolecular hydrogen bond of 3-OH...O-5 and the intermolecular hydrogen bond of 6-O...HO3', respectively[1]. These three bands of samples preprocessed had red shift, which indicated that the hydrogen-bonding network of MCC changed after the preprocessing.

\section{References:}

[1] Oh SY, Yoo DI, Shin Y, et al. Crystalline structure analysis of cellulose treated with sodium hydroxide and carbon dioxide by means of X-ray diffraction and FTIR spectroscopy. Carbohydrate research. 2005;340(15):2376-91.

\section{Preprocessing conditions \& Information of samples:}

Temperature: $120^{\circ} \mathrm{C}$

Pressure: $10 \mathrm{MPa}$

\begin{tabular}{|c|c|c|c|}
\hline Sample number & $\begin{array}{c}\text { steam explosion } \\
\text { frequency }\end{array}$ & feeding modes & steam explosion times \\
\hline A(raw MCC) & - & - & - \\
\hline B & $30 \mathrm{~Hz}$ & one-time feeding & once \\
\hline C & $40 \mathrm{~Hz}$ & $\begin{array}{c}\text { continuous and uniform } \\
\text { feeding }\end{array}$ & once \\
\hline D & $40 \mathrm{~Hz}$ & two-time feeding & twice \\
\hline E & $40 \mathrm{~Hz}$ & one-time feeding & once \\
\hline
\end{tabular}




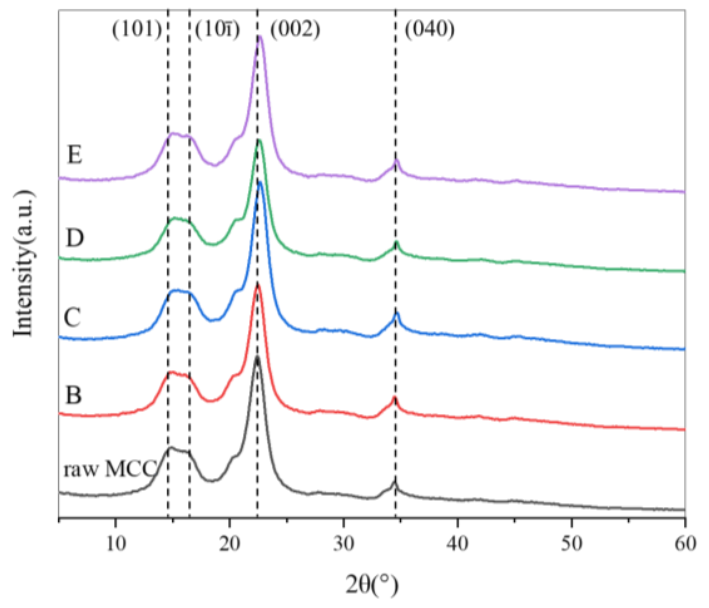

Figure 1. XRD patterns of all samples.

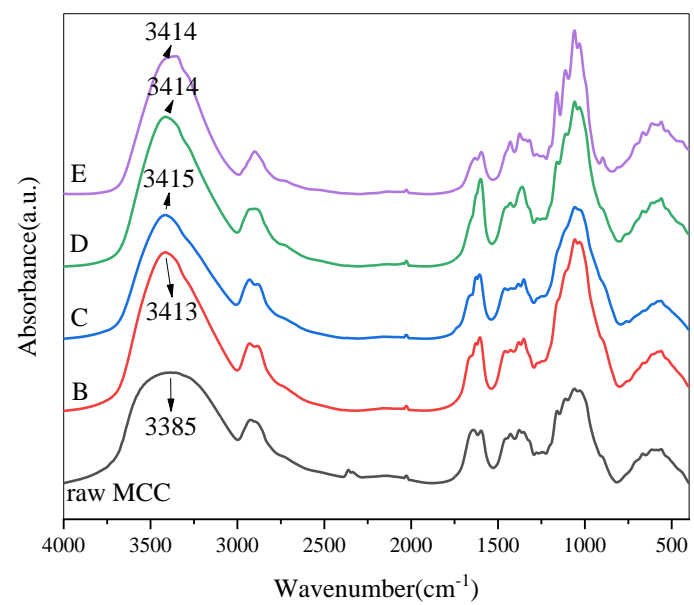

Figure 2. FTIR spectrum of all samples.

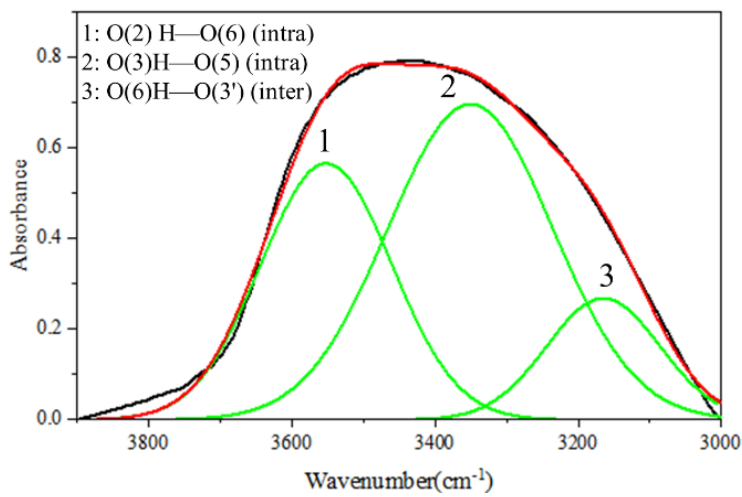

Figure 3. Resolution of hydrogen-bonded $\mathrm{OH}$ stretching for raw MCC. 